\title{
A study on clinical outcome of obstructed labour
}

\author{
Indra ${ }^{1}$, Usharani $\mathrm{N}^{2 *}$, Mumtaz Bendigeri ${ }^{2}$
}

\begin{abstract}
${ }^{1}$ Department of Obstetrics and Gynecology Sri Siddhartha Medical College, Tumkur, Karnataka, India
${ }^{2}$ Department of Obstetrics and Gynecology, VIMS, Bellary, Karnataka, India
\end{abstract}

Received: 27 December 2016

Accepted: 02 January 2017

\section{*Correspondence:}

Dr. Usharani N.,

E-mail: ushadrrani@gmail.com

Copyright: ( ) the author(s), publisher and licensee Medip Academy. This is an open-access article distributed under the terms of the Creative Commons Attribution Non-Commercial License, which permits unrestricted non-commercial use, distribution, and reproduction in any medium, provided the original work is properly cited.

\begin{abstract}
Background: Obstructed labour accounts for $8 \%$ of maternal mortality in developing countries. Obstructed labour is the single most important cause of maternal death and is one of the three leading causes of perinatal mortality with the case fatality rate of $87-100 \%$.

Methods: The 50 patients with prolonged labour and maternal distress with signs and symptoms of maternal exhaustion, dehydration, keto-acidosis, Bandl's ring formed the study subjects.

Results: Out of the 50 cases studied the still birth rate was $24 \%$ (12 cases). This was due to delay in the referring the cases from peripheral centers.

Conclusions: Our peripheral hospital need appointment of qualified personnel and well trained staff, who can recognize any deviation from normal labour and recognize malpresentation and malposition at the earliest and refer such cases to higher centers.
\end{abstract}

Keywords: Maternal death, Obstructed labour, Perinatal morbidity

\section{INTRODUCTION}

Obstructed labour is seen when the progressive descent of the presenting part is arrested due to mechanical obstruction despite good uterine contractions. ${ }^{1}$ It is due to a mismatch between the fetal size more precisely the presenting part of fetus, and the mothers pelvis. ${ }^{2}$ The mismatch may be due to genuine disproportion when the vertex is in the occipito anterior position or relative disproportion due to deflexion and malposition. ${ }^{3}$

It is a condition where further progress of labor is not possible without assistance. ${ }^{4,5}$ Labour is considered obstructed when the presenting part of the fetus cannot progress into the birth canal, despite strong uterine contractions. ${ }^{6}$ It is more common in humans than in primates because the birth canal of a woman is not as straight and wide as in primates. ${ }^{7}$ Obstructed labour (OL) is a major cause of both maternal and new-born morbidity and mortality. The obstruction can only be alleviated by means of an operative delivery, either caesarean section or other instrumental delivery. ${ }^{6}$ Obstructed labour ranked $41^{\text {st }}$ in GBD 1990, representing $0.5 \%$ of the burden of all conditions and $22 \%$ of all maternal conditions. It was estimated to be the most disabling of all maternal conditions. ${ }^{6}$ Each year, 210 million women become pregnant, of whom 20 million will experience pregnancy-related illness and 500,000 will die as a result of the complications of pregnancy or childbirth. $^{7}$

In 1987, the World Health Organization (WHO) launched the Safe Motherhood Initiative, which aimed to reduce maternal morbidity and mortality by $50 \%$ by the year 2000. The initiative did not succeed but maternal health continues to be a major focus of WHO effort. The current WHO initiative is to reduce maternal mortality to $75 \%$ of the 1990 level by $2015 .{ }^{9}$ If this is to be successful, the problem of obstructed labour will need to be addressed effectively. Obstructed labour accounts for $8 \%$ of maternal mortality in developing countries. ${ }^{10}$ Obstructed labour is the single most important cause of maternal 
death and is one of the three leading causes of perinatal mortality with the case fatality rate of $87-100 \% .^{2}$ Obstructed labour is seen between $0.56-1.89 \%$ of all deliveries in the referral hospitals of India. ${ }^{1}$ Obstructed labour is the leading cause of hospitalization comprising up to $39 \%$ of all obstetric patients in low resource countries.12 It is found to be directly or indirectly responsible for half of all maternal deaths affecting mainly Primigravida and grand multipara. ${ }^{13}$ Reports from India, Nigeria, Ghana, Ethiopia and Bangladesh indicate that up to $5 \%$ of cases of uterine rupture are seen with unscarred uterus and obstructed labour is one of the top 5 causes of maternal mortality.

Even at present as many as $4 \%$ mothers dies who fall into this grave situation. Obstructed labour is therefore an absolute but not a relative condition. In recent years, increased attention has been focused upon the disparity between developed and developing countries in levels of maternal and perinatal mortality. The term social obstetrics has drawn the attention of obstetricians in developing countries. Ignorance, non-availability of transport and medical facilities are important causes. In our country where $>50 \%$ of the people reside in rural areas the obstetric care of these rural mothers is quite deplorable. Most deliveries are still conducted by untrained personnel. Poor quality and difficult access to obstetric care over-shadows all other factors in producing higher obstetric morbidity and mortality.

Most of these maternal deaths are found in unbooked cases. The role of destructive operations in obstructed labour cases with dead or moribund foetuses has been found to be superior to caesarean sections in many studies. On balance, it seems prudent to individualize the case, depending on the obstetrician's skill and experience to select the method of delivery for the best outcome. Improved quality of judgment and skilled surgery may be superior even in adverse environment. On the contrary, if the condition of the patient is poor, even improved ancillary aids and good environment cannot improve the result significantly.

\section{METHODS}

The study was conducted at the Department of Obstetrics and Gynecology, tertiary care hospital.

\section{Inclusion criteria}

- Longer duration of labour pain $>18$ hours

- Those patients with prolonged labour and maternal distress with signs and symptoms of maternal exhaustion, dehydration, keto acidosis, Bandl's ring.

\section{Exclusion criteria}

No signs and symptoms of obstructed labour

\section{Sample size: 50}

\section{Investigations}

- $\quad$ CBC, Blood grouping and Rh typing

- Blood urea, serum creatinine

- Urine for protein, Sugar and ketone

- High vaginal swab for culture and sensitivity

- If sign and symptoms suggest of septicemia blood culture and sensitivity

- Planned urgent delivery either by caesarean or vaginal delivery and these cases were followed until discharge from the hospital for fetal and maternal outcome

\section{RESULTS}

The incidence of obstructed labour is more in Primigravida. In present study 54\% of patients were primigravidas.

Table 1: Distribution of study subjects based on booking status.

\begin{tabular}{|lll|}
\hline Booking status & Frequency & Percentage \\
\hline Booked & 20 & 40.0 \\
\hline Unbooked & 30 & 60.0 \\
\hline Total & 50 & 100.0 \\
\hline
\end{tabular}

In the current study it was found that the major cause of obstructed labour was CPD comprising of $52 \%$ of cases. The second common cause being malposition. In our study it was found that $4 \%$ of the cases had Bandl's ring at the time of admission.

In the current study $96 \%$ of the cases had abdominal delivery. $4 \%$ had vaginal delivery. The rate of CS was highest in our study. Treatment was aimed at relieving the obstruction without any delay in view of decreasing the morbidity.

In the study conducted, major operative procedure performed was LSCS. Out of 50 cases there were 4 cases of rupture. Subtotal hysterectomy was done in 1 case. In the remaining three cases repair of the rupture with sterilization was done.

Table 2: Distribution of study subjects based on gravida.

\begin{tabular}{|lll|}
\hline Gravida & Frequency & Percentage \\
\hline 1 & 27 & 54.0 \\
\hline 2 & 7 & 14.0 \\
\hline 3 & 10 & 20.0 \\
\hline 4 & 5 & 10.0 \\
\hline 5 & 1 & 2.0 \\
\hline Total & 50 & 100.0 \\
\hline
\end{tabular}


Table 3: Distribution based on duration of labour.

\begin{tabular}{|lllll|}
\hline Duration of labour & Frequency & Primigravida & Multigravida & Percentage \\
\hline $18-24$ hours & 35 & 12 & 23 & 70.0 \\
\hline$>24$ hours & 15 & 15 & - & 30.0 \\
\hline Total & 50 & 27 & 23 & 100.0 \\
\hline
\end{tabular}

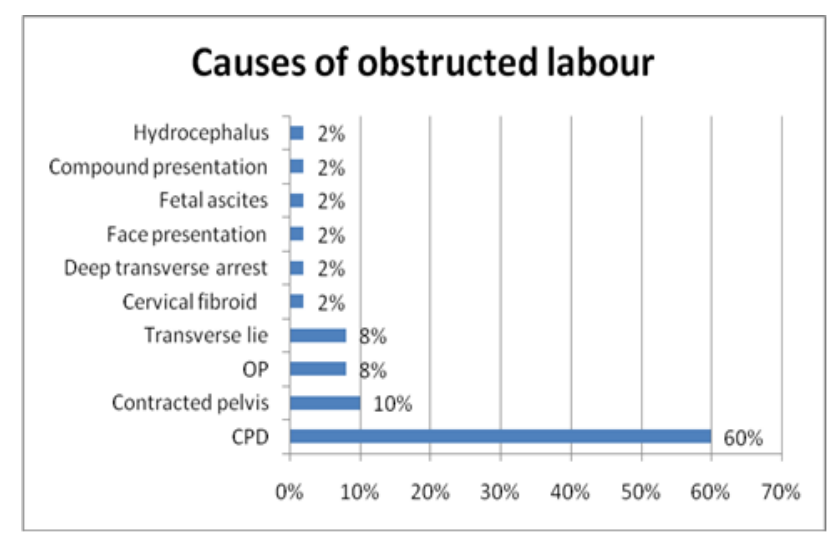

Figure 1: Causes of obstructed labour.

Table 4: Distribution of study subjects based on presence of Bandl's ring.

\begin{tabular}{|c|c|c|}
\hline Constriction ring & Frequency & Percentage \\
\hline Absent & 48 & 96.0 \\
\hline Present & 2 & 4.0 \\
\hline Total & 50 & 100.0 \\
\hline
\end{tabular}

The most common complication following obstructed labour was paralytic ileus which constituted 16 cases $(50 \%)$. The next most common complication was anemia as a sequel to PPH. Puerperal sepsis was found in 12 $(24 \%)$ cases.

Table 5: Mode of delivery.

\begin{tabular}{|llll|}
\hline Delivery & Abdominal & Vaginal & Total \\
\hline Frequency & 48 & 2 & 50 \\
\hline Percent & $96 \%$ & $4 \%$ & $100 \%$ \\
\hline
\end{tabular}

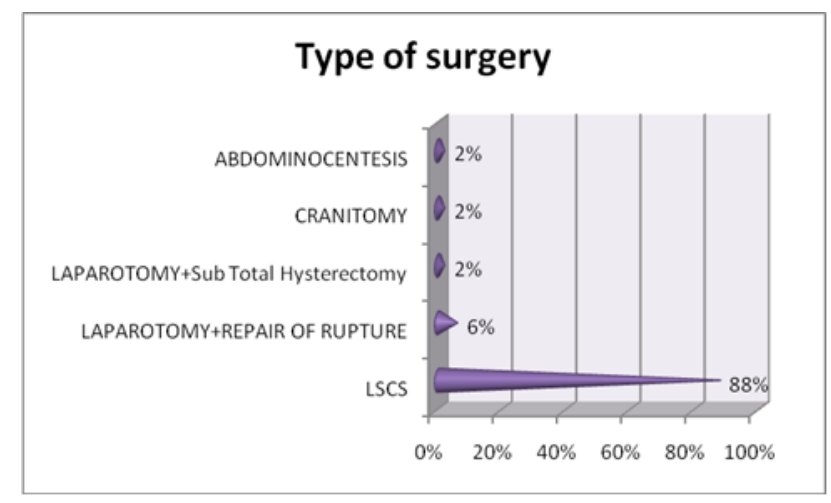

Figure 2: Type of surgery.

\section{Incidence of maternal mortality}

The maternal mortality in this study was $2 \%$. The death was due to septicemia. Factors influencing maternal mortality are unbooked cases, extremes of age in reproductive period, high parity and low socio economic status.

\section{Perinatal outcome}

Obstructed labour is one of the most important causes of Preventable perinatal mortality. The perinatal mortality was over $23 \%$ in Bhattacharya et al and if the fetus survives, the morbidity is greatly enhanced due to anoxia, intracranial haemorrhage and septicemia.

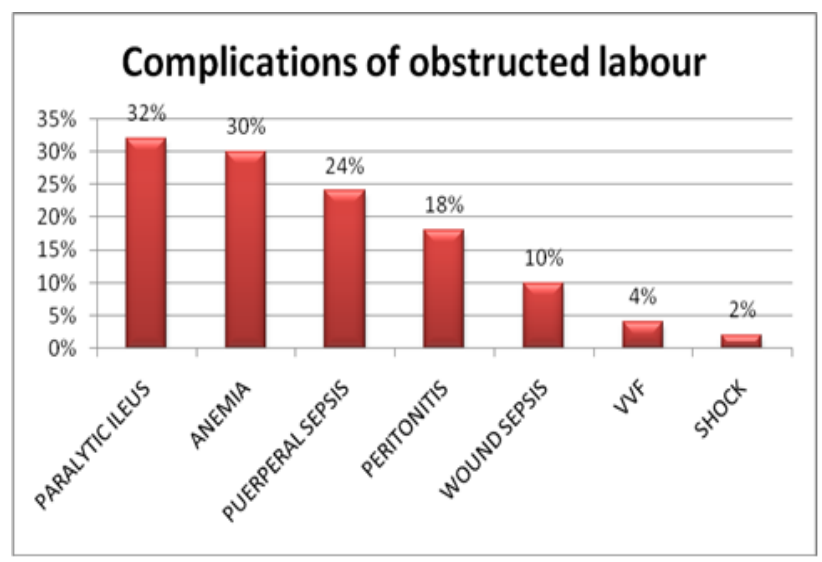

Figure 3: Complications of obstructed labour.

Out of the 50 cases studied the still birth rate was $24 \%$ (12 cases). This was due to delay in the referring the cases from peripheral centers.

Table 6: Distribution based on perinatal outcome.

\begin{tabular}{|lll|}
\hline Perinatal outcome & Frequency & Percentage \\
\hline Live & 38 & 76.0 \\
\hline Still born & 12 & 24.0 \\
\hline Total & 50 & 100.0 \\
\hline
\end{tabular}

\section{DISCUSSION}

According to Rao B, 5-8\% of hospital deliveries in India are emergency admission. ${ }^{14}$ Both maternal morbidity and neonatal mortality were observed to be more in these cases. 
This picture can be improved by giving good antenatal check-up and health education to these patients at their door steps by trained health care professionals. Availability of specialised professionals at the level of PHCs can probably improve the situation

The incidence of obstructed labour is more in Primigravida. In our study $54 \%$ of patients were primigravidas.

The high incidence is due to delayed recognition of disproportion. Risk of PNM is also high in Primigravida with obstructed labour. In a study conducted by Ara A, obstructed labour was more common among Primigravida involving $40.8 \%$ of the cases. ${ }^{15}$ In a study by Shugufta et al the incidence of primigravida was $46.15 \%$ which is comparable to our study. ${ }^{16}$

In the current study it was found that the major cause of obstructed labour was CPD comprising of $52 \%$ of cases. The second common cause being malposition. Comparing my study with other studies, the cause for obstruction was CPD in $87.18 \%$ in a study by Shagufta. ${ }^{16}$

A study by Ara A showed the leading cause for obstruction was CPD comprising $47.5 \%$ of all the cases. ${ }^{15}$ The perinatal mortality shows a declining trend. In our study the perinatal mortality rate was $40 \%$.

Table 7: Comparing our study with the perinatal mortality of the other studies.

\begin{tabular}{|llll|}
\hline Authors & Locality & Year & PNM rate \\
\hline Jayaram K & Guntur & 1993 & $76.6 \%$ \\
\hline Adhikari et al & Kolkata & 2005 & $43.2 \%$ \\
\hline $\begin{array}{l}\text { Bhattacharya } \\
\text { et al }\end{array}$ & Indore & 2007 & $23.21 \%$ \\
\hline
\end{tabular}

\section{CONCLUSION}

Obstructed labour which is a preventable condition still prevails as an important obstetric problem in our country. This condition results in high maternal and perinatal morbidity. Hence it is a condition which is best prevented rather than to be treated. The incidence of obstructed labour can be brought down by improving our health care system, especially at the peripheral areas.

Funding: No funding sources Conflict of interest: None declared

Ethical approval: The study was approved by the Institutional Ethics Committee

\section{REFERENCES}

1. Adhikari SM, Dasgupta M. Management of obstructed labour: A retrospective study. Journal Obs Gyna Ind. 2005;55(1):48-51.

2. Neilson JP, Lavender S. Obstructed labour. British Medical Bulletin. 2003;67(1):191-204.

3. EL-Hamamy E, Arulkumaran A. Poor progress of labour. Current Obstet Gynecol. 2005;15:1-8.

4. Lawson GB. Obstructed labour. In obstetrics and gynaecology in the tropics and developing countries. London .Edward Arnold Press. 1967:172-202.

5. Konje JC, Obisesan KA. Obstructed labour in Ibadan. Int J Gynecol and Obstet. 1992;39:17-21.

6. Dolea C, AbouZahr C. Global burden of obstructed labour. 2000.

7. AbouZahr C. Prolonged and Obstructed labour. In: Murray CJL and Lopez AD, Eds Health Dimensions of sex and reproduction: the global burden of sexually transmitted diseases, maternal conditions, perinatal disorders and congenital anomalies WHO. 1998.

8. McCarthy M. What's going on at WHO? Lancet. 2002;360:1108-10

9. McCarthy M. A brief history of at WHO? Lancet. 2002;360:1111-2

10. Cron J. Lessons from the developing world: Obstructed labour and the vesico vaginal fistula Obs Gyn and Womens Health Medscape General Medicine. 2003;5(3).

11. Weeks A, Lavender T. Personal accounts of "near miss" maternal mortalities in Kampala, Uganda. BJOG. 2005;112 (9):1302-7.

12. Mekbib T, Kassaye E, Getachew A. FIGO Save the mothers Initiative. Ethiopia-Sweden Collaboration. Int J Gynaec Obstet. 2003;81(1):93-102.

13. Kumar R, Sharma K. Maternal mortality inquiry in all rural community in northern India. Int $\mathrm{J}$ Gynecol Obstet.1986;29(4):313-9.

14. Ara A. Outcome of Obstructed labour. Int J Gynaec Obstet Original. 2011;18(3).

15. Rather SY, Qureshi A, Praveen S. Obstructed laborcurrent scenario in a developing country. The Internet Journal of Gynecology and Obstetrics. 2010;13(2).

16. Joud DOE. Dystocia: a study of its frequency and risk factors in 7 cities of West Africa. Int J Obsteric Gynecol. 2001;74:171-8.

Cite this article as: Indra, Usharani $\mathrm{N}$, Bendigeri $\mathrm{M}$. A study on clinical outcome of obstructed labour. Int J Reprod Contracept Obstet Gynecol 2017;6:439-42. 